\title{
Development of Neural Stem Cell-Based Therapies for Parkinson's Disease
}

\author{
Jiunn-Tay Lee, Chia-Kuang Tsai and \\ Chung-Hsing Chou \\ Additional information is available at the end of the chapter
}

http://dx.doi.org/10.5772/intechopen.73870

\begin{abstract}
Neural stem cell (NSC)-based therapies, such as cell transplantation, are an emerging strategy for restoring neuronal function in Parkinson's disease (PD), which is characterized by a profound and selective loss of nigrostriatal dopaminergic (DA) neurons. Advanced researches on the microenvironment of grafted cells will promote clinical applications of NSCs for neurological disorders. A novel cell culture model of the neurovascular network was therefore devised to investigate autocrine, paracrine, and juxtacrine signaling in the neurovascular unit generated by NSCs and vascular endothelial cells. Preclinical studies using cutting-edge technologies, including cellular reprogramming, advancement in scaffolds for brain tissue engineering, image-guided injection, and noninvasive monitoring of tissue regeneration will pave the way for successful clinical trials of NSC-based therapies for PD. Once the implanted or regenerated DA neurons are integrated into the existing nigrostriatal DA pathway, the symptoms of PD can potentially be alleviated by reversing characteristic neurodegeneration.
\end{abstract}

Keywords: neural stem cell, Parkinson's disease, endothelial cell, neurovascular unit, regenerative medicine, tissue engineering, cell transplantation

\section{Introduction}

Parkinson's disease (PD) is the most common neurodegenerative movement disorder, and its prevalence reaches $0.3 \%$ of the entire population in industrialized countries [1]. PD prevalence is increasing with age, affecting $1 \%$ of the population above 60 years and $4 \%$ in those aged over 80 [2]. Since the clinical trial of neural stem cell (NSC) transplantation therapy has shown promising results for stroke patients [3], the NSC-based therapy could be a potential treatment 
for restoring neuronal function for PD patients. A better understanding of pathophysiology of PD, establishment of valid and effective NSC lines, and successful clinical trials will point to a novel neuroregeneration strategy to complement current medical treatment and deep brain stimulation.

Advances in the pathophysiology of PD have expanded our traditional knowledge that it is characterized by a profound and selective loss of nigrostriatal dopaminergic (DA) neurons. PD could be considered a developmental disorder with evidence beyond neurodegeneration, regarding relationships among deregulated neurogenesis, disease onset, and its progression. The numbers of proliferating NSCs, for instance, have been found decreased in the PD-affected postmortem brain $[4,5]$, but evidence of a link between altered proliferation of NSCs, functional DA neurons, and neurological deficits remains insufficient. Besides typical motor symptoms, including asymmetrical bradykinesia, rigidity, postural instability, and resting tremors, patients may have nonmotor symptoms, such as dementia, sleep disturbance, and autonomic dysfunction. Hence, public health education and routine physical examinations are substantial for early diagnosis and intervention.

NSCs preserve the ability to self-renew and differentiate into all neural lineage cells, and they are regarded as a potential graft for cellular transplantation. Reducing the possibility of tumorigenesis has to be considered during immortalization of NSC lines which provide a consistency of cell grafting. Furthermore, preclinical studies, such as transcranial injection of NSCs into animal brains with adequate follow-ups, will prove the validity of its clinical application.

Independent ethical and regulatory approval, full financial support from the foundation, and long-term follow-up of systematically collected rigorous measures are the requirements for conducting clinical trials for NSC-based therapies in PD. Appropriately transparent processing with governmental approval could encourage patient cooperation according to experience from cell transplantation therapy in other diseases. In this chapter, we will provide a comprehensive literature review as well as the perspectives on NSC applications in PD.

\section{Neuronal loss in Parkinson's disease}

The pathological diagnosis of PD has been possibly made since Frederic Lewy described microscopic particles in affected brains as early as 1912, later named "Lewy bodies" [6]. The characteristic pathophysiology of PD includes death of DA neurons in the substantia nigra pars compacta $(\mathrm{SNpc})$, degeneration of DA neurotransmission, and the presence of alphasynuclein and protein inclusions in neuronal cells that are known as Lewy bodies [7]. In general, more than $50 \%$ of DA neurons have been lost before typical symptoms of PD develop [8]. It has been found that a $20 \%$ decrease in nigral neuronal cell density in incidental Lewy body disease compared with controls [9]. Additionally, nigral neuronal loss could be observed before the appearance of alpha-synuclein aggregates [9]. A negative correlation between neuronal density and local alpha-synuclein burden in the substantia nigra was therefore evident in PD patients. Most importantly, stage-dependent nigral neuronal loss and local burden of alpha-synuclein pathological conditions are closely coupled during disease progression of PD. 
The diagnosis of PD can be made through the detection of mutations in specific genes responsible for familial PD in the era of molecular biology. But only about $10 \%$ of diagnosed patients are found carrying identifiable pathological mutations, and the majority of PD cases are sporadic [2]. Several of the PD-associated genes are related to mitochondrial dysfunction although most are of unknown or poorly understood function. Three of the genes associated with a recessive, early-onset form of the disease (DJ-1, PINK1, Parkin) are directly linked to mitochondrial function, providing a potential connection with changes associated with aging [10]. DJ-1 is a mitochondrially enriched, redox-sensitive protein, and it is able to signal oxidative challenges and potentially coordinate a variety of mitochondrial oxidative defense mechanisms [11, 12]. Parkin and PTEN-induced putative kinase 1 or PINK1 also have mitochondrial roles $[13,14]$.

The strongest risk factor in PD is age, beyond the other three best-documented pan-cellular factors, including genetic mutations, environmental toxins, and inflammation [2, 15]. It is widely speculated that declining mitochondrial function is a key factor why age is such a strong risk factor $[10,16]$. However, the pattern of neuronal pathology and cell loss in PD is difficult to explain without cell-specific factors. It has been proposed that the opening of L-type calcium channels during autonomous pacemaking results in sustained calcium entry into the cytoplasm of SNc DA neurons and accordingly the increase in mitochondrial oxidant stress and susceptibility to toxins [15]. This cell-specific stress could increase the negative consequences of pan-cellular factors. Therefore, antagonists for L-type calcium channels have been proposed to complement current attempts to boost mitochondrial function in the early stages of PD [17], but there is still lack of strong evidence in its therapeutic effects.

\section{Neural stem cells and adult neurogenesis}

In the adult mammalian brain, NSCs are largely restricted to two regions: the subependymal zone (SEZ) of the lateral ventricles and the subgranular zone (SGZ) of the dentate gyrus in the hippocampal formation $[18,19]$. The NSC niche can be regarded as a specialized neurovascular unit (NVU) because the vasculature plays an indispensable role for maintaining the stem cell niche [20]. The NSC niche in the adult SEZ contains an extensive planar vascular plexus with specialized properties. Within such a unique NVU, endothelial cells (ECs) exert their influence over NSCs to regulate fate specification, differentiation, quiescence, and proliferation, through direct contact and paracrine signaling [20]. For example, a U-shaped gradient of the soluble factor, stromal cell-derived factor 1 (SDF-1), established by both ependymal and endothelial cells, helps guide SEZ quiescent NSCs moving from the ependymal niche to the endothelial niche, where they are activated [21]. Endothelial factors, including SDF-1, therefore have differential effects on neural progenitor populations. The vessels also produce a laminin-rich extravascular basal lamina, which is organized into branched structures known as fractones, regulating NSC behaviors via direct contact [22]. Interestingly, vascular pericytes in the central nervous system (CNS) have been found to possess the ability of differentiating into vascular and neural lineage cells [23], in addition to the originally defined functions of pericytes, such as controlling cerebral blood flow and limiting blood flow by constricting capillaries [24, 25]. 
At the interface of neural and vascular compartments in the CNS is the blood brain barrier (BBB), which is the first barrier leading to transport limitations for both cellular and acellular elements. Paul Ehrlich demonstrated the integrity of this barrier first in 1885 when he injected vital dyes into the circulatory system and observed that all organs except the brain and the spinal cord were stained [26]. The integrity of this barrier was attributed to ECs and could be examined with an electron microscope demonstrating the tight junctions [27]. The barrier function of endothelium is considered a hallmark feature when validating models of the BBB. It is also important to assess the barrier function while culturing ECs with other types of cells comprising the NVU in order to investigate adult neurogenesis [28].

The CNS endothelium is not only the inner lining of the blood vessel, but also an active participant in many signaling pathways. Brain-derived neurotrophic factor (BDNF), for instance, is one of the endothelium-secreted factors affecting the behaviors of NSCs [29, 30]. Blood capillaries may regulate NSCs through interactions via collagen IV and laminin in the basal lamina [31]. Blood vessels also provide an access to circulate systemic factors, including glucocorticoids, sex hormones, and prolactins. The barrier properties of the BBB allow only certain molecules to cross the endothelium. The BBB is maintained when endothelium has a prevalence of tight junctions and specific transport proteins. The BBB is characterized by an organ-specific high transendothelial electrical resistance (TEER, up to $5000 \mathrm{ohm} \cdot \mathrm{cm}^{2}$; in contrast with placental TEER $20-50 \mathrm{ohm} \cdot \mathrm{cm}^{2}$ ) [32, 33]. The BBB is the major site for the exchange of molecules between the blood and the CNS, given the small diffusion distance to neurons. Proximity of the finest branches of brain capillaries to individual neurons is typically $8-25 \mu \mathrm{m}$ [34].

In the neurogenic niche of the mouse brain, the basal processes of NSCs contact the vasculature, and at these sites of contact, a modified BBB exists that lacks astrocytic endfeet and pericytic coverage [20]. Direct physical contact between the brain capillary ECs and the NSCs reflects their intimate relationships. Juxtacrine signaling is therefore essential for devising a NVU model using ECs and NSCs. A NVU with direct contact between NSCs and ECs provides a neurovascular network, where the concentration of soluble factors recently released from nearby cells can remain high locally, and this cannot be observed using the transwell co-culture system. Furthermore, extracellular matrix (ECM) molecules produced by ECs and NSCs, which mediate cell differentiation and tissue morphogenesis, are involved in contactdependent signaling between NSCs and ECs. The firm adhesion of cells to an ECM is indispensable to a cell culture model of three-dimensional cytoarchitecture for investigating NSCs and adult neurogenesis within a specific NVU.

\section{Paracrine and juxtacrine signaling in the neurovascular unit}

To devise an advanced NVU model and to promote NSC-based therapies may benefit from studies on the neurovascular development. Accumulating evidence shows that shared molecules and coordinated cellular mechanisms regulate the development of vascular and neuronal systems $[35,36]$. Neurogenesis and angiogenesis are also found co-regulated in both embryonic 
and adult brains, as well as damaged brains. To date, most of this evidence has been obtained from in vivo experiments [37, 38]. Transgenic animal models were commonly used for these studies because relevant human material was still limited. A major technical difficulty in using these primary tissues is that numerous types of cells interact with each other in a very thin compartment. The ECs, for example, are not easily isolated for both qualitative and quantitative biochemical analysis.

Alternatively, ex vivo organotypic NVU model systems consisting of the slice of brain and brain ECs have been applied to experiments studying crucial BBB parameters such as TEER and transport mechanisms [39]. Researchers using cortical organotypic slice cultures or SEZ whole mounts [40] are able to observe the cellular interactions within a relatively complete but complicated system. In contrast, experiments using in vitro cell culture models of the NVU provide a useful tool in order to disentangle intercellular paracrine, autocrine, and juxtacrine signaling.

\subsection{Paracrine signaling}

Paracrine signaling is a form of cell-to-cell communication in which the target cell is close to the signaling cell and the secreted and diffusible signal molecule affects only nearby target cells. During CNS development, common signaling molecules guide vascular and axonal outgrowth via paracrine mechanisms, and these factors may have to be considered in NSCbased therapies in PD. For example, growth cones of axons project numerous filopodia that actively extend and retract in response to four families of extracellular guidance cues: ephrins, semaphorins, netrins, and slits [41]. Guidance cues can be divided into attractive or repulsive signals. These cues are cell-membrane-bound acting on nearby axons or secreted forming gradients that influence the trajectories of extending axons [41].

\subsubsection{NSC paracrine signaling to EC}

The brain vascular system develops from the cephalic mesenchyme through the sprouting of capillaries into the brain parenchyma. This process is regarded primarily as angiogenesis which refers to the de novo formation of blood vessels by the sprouting and splitting of vessels already established by vasculogenesis [42]. Vascular endothelial growth factor (VEGF) has been implicated in the control of CNS angiogenesis. The temporal and spatial expression of VEGF is consistent with the hypothesis that VEGF is synthesized and released by the ventricular neuroectoderm and may induce the ingrowth of capillaries from the perineural vascular plexus [43]. Upon entering the CNS parenchyma, blood vessels migrate along a preformed latticework of neuroepithelia and radial glia, which are NSCs and neural progenitors that give rise to differentiated neurons and astrocytes [44].

VEGF is strongly expressed by NSCs in the ventricular zone. VEGF is a key signal orchestrating vascularization of the neuroectoderm [45]. At the tips of vascular sprouts, the leading endothelial tip cells extend filopodia toward hypoxic regions where higher VEGF is produced [46]. Tip cells react to VEGF via VEGF receptor 2 (VEGFR2) expressed on filopodia. Tip cells 
produce high levels of the Notch ligand delta-like 4 (Dll4) that activates Notch signaling on adjacent ECs. These ECs then differentiate into stalk cells, which form the stalk of the sprouting vessel with a lumen that allows for blood flow and tissue oxygenation [47]. Stalk cells down-regulate expression of VEGFR2 and VEGFR3 and increase levels of the decoy receptor VEGFR1, thus becoming less sensitive to VEGF [48]. These studies suggest that VEGF/VEGFR2 is one of the signaling pathways involved in angiogenesis and is also important for neurogenesis during CNS development.

\subsubsection{EC paracrine signaling to NSC}

Vascular-derived neurotrophic factors, such as BDNF, are key factors in the co-ordination of vascular and neural development [49]. In a co-culture experiment using transwell inserts, mouse ECs released soluble factors that stimulated the self-renewal of mouse NSCs and inhibited their differentiation [50]. Depending on the culture condition, mouse ECs may favor maintenance of the progenitor phenotype of mouse NSCs through the production of soluble factors or to promote neuronal differentiation through direct contact [51].

\subsection{Autocrine signaling}

Autocrine signaling is a form of cell signaling in which a cell secretes a substance that binds to its own surface receptors, leading to changes within the cell. Initially discovered for their role in axon guidance during vessel formation, VEGFs and their high-affinity tyrosine kinase VEGF receptors are now implicated in the development of the CNS [52]. In embryonic mouse forebrain and embryonic cortical neurons grown in vitro, VEGF acts as an autocrine survival factor for VEGFR2-expressing postmitotic neurons [53]. In the adult rat brain, VEGFR2 is expressed by neuronal progenitors in the SEZ, and intracerebral administration of VEGF-A stimulates both neurogenesis and angiogenesis in the SEZ and hippocampus [54].

\subsection{Juxtacrine signaling}

Juxtacrine is a type of cell-to-cell or cell-to-ECM signaling that requires close contact. This stands in contrast to autocrine or paracrine signaling, where a signaling molecule is released and diffused into extracellular space [55]. Cell-to-cell communication between blood vessels and glia cells in the NVU occurs primarily via intervening vascular basement membranes that contain a variety of growth factors and ECM proteins [56].

Juxtacrine signaling is indispensable for neuroblasts migrating along blood vessels as neuroblasts primarily interact with the ECM surrounding astrocyte endfeet in a vasophilic migration model in the mouse brain [57]. In the SEZ neurogenic niche, NSCs differentiate into neural progenitors (NPCs) which have a limited proliferative ability and does not exhibit self-renewal. The relatively quiescent NPCs give rise to rapidly dividing transit-amplifying cells which further differentiate into neuroblasts. These neuroblasts sense microenvironmental cues and migrate tangentially from the SEZ to the olfactory bulb along rostral migratory stream (RMS). 


\section{Restoration of the disrupted neurovascular microenvironment by tissue and cell transplantation}

Tissue regeneration or cell replacement for loss of DA neurons is a potential approach for PD. Since the late 1980s, over 300-400 PD patients worldwide have received transplants of human fetal ventral mesencephalic (VM) tissue, which is rich in postmitotic DA neurons [58]. Two double-blind, placebo-controlled trials of VM transplants for PD patients, however, showed variable efficacy and occurrence of side effects, such as "off-medication" and "graft-induced dyskinesias" (GIDs) [59, 60]. It was observed that the PD pathologic process might propagate from host to grafted cells, and the presence of Lewy bodies in grafted neurons suggests hostto-graft disease propagation [61]. Implanted neurons could be affected by the disease process and did not function normally. Parkinson's pathogenesis or GIDs therefore could propagate from host to grafted cells although recipients had experienced long-term symptomatic relief with the majority of grafted cells functioning unimpaired. On the other hand, CNS involvement of graft versus host disease (GvHD) has been found as a cause of CNS disorders after allogeneic hematopoietic stem cell transplantation (allo-HSCT) which is administered systemically [62]. Although transplantation of fetal tissue or stem cells was conducted transcranially instead for PD patients, the rare heterogeneous chronic CNS GvHD symptoms might happen with cerebrovascular manifestations, demyelinating disease, or immune-mediated encephalitis. GvHD could be prevented or treated with immunosuppressant such as corticosteroids, but CNS-related GvHD after allo-HSCT is associated with a poor prognosis.

GIDs could be serious side effects after transplantation of fetal VM tissue for PD patients. Clinical pattern and risk factors for dyskinesias following fetal nigral transplantation in PD have been investigated [63]. On-medication dyskinesias are typically generalized and choreiform. In contrast, off-medication dyskinesias are usually repetitive, stereotypic movements in the lower extremities with residual Parkinsonism in other body regions. Off-medication dyskinesias are common following transplantation and may represent a prolonged form of diphasic dyskinesias which are associated with partial or incomplete dopaminergic reinnervation of the striatum [63]. The pathophysiological mechanism underlying GIDs can be partially attributed to excessive serotonergic innervation in the grafted striatum of patients who developed off-medication dyskinesias later following the initial improvement of motor symptoms after transplantation. It has been realized that the dyskinesias can be markedly attenuated by systemic administration of a serotonin [5-hydroxytryptamine (5-HT)] receptor (5-HT1A) agonist [64]. A recent study demonstrated a mechanistic link between serotonin 5-HT6 receptor or a cyclic adenosine monophosphate (cAMP)-linked designer receptors exclusively activated by designer drugs (DREADD), intracellular CAMP, and GIDs since exclusive activation of serotonin 5-HT6 receptor, located on the grafted DA neurons, is sufficient to induce GIDs [65]. GIDs resulting from cell therapies for PD with fetal tissue or stem cells are therefore possibly avoided and treated with serotonin receptor agonists.

The TRNSEURO (NCT01898390), a multicenter European initiative on PD transplantation using fetal VM tissue, has been conducted since 2012, in an attempt to overcome obstacles such as inconsistent methods between the previous trials [66]. The issues on administration of 
immunosuppressant and anticonvulsant, the method of graft preparation, and the precise site of graft placement will be further resolved. However, heterogeneous compositions of the graft, difficulties in standardization of cellular material, and ethical concerns are limitations in these trials using fetal VM tissue. In addition, complications associated with procedures of transplantation, such as subdural hematoma, have to be prevented [59].

NSCs preserve the ability to self-renew and differentiate into all neural lineage cells, including neurons, astrocytes, and oligodendrocytes, and they are therefore a source of potential graft for cellular transplantation in neurological disorders. Together with ECs and pericytes, NSC can constitute the functional NVU for tissue restoration in PD. Since neurons are integrated into the neurovascular network with other cellular and acellular compositions in the NVU, combined transplantation of NSCs with other types of cells or biomaterials may be more efficacious for tissue replacement. Local factors within the microenvironment of transplanted NSCs affect the fate of the cells, as measured by survival, proliferation, differentiation, and neurogenesis [67]. Several groups have studied modulation of stem cells or DA cells with combined cellular transplantation in animal models of PD (Table 1) [68]. Besides the attempt to replace damaged tissues, it was shown that grafted cells may promote endogenous vasculogenesis and neurogenesis in the neighboring tissues [69].

To administer cell transplantation therapies, NSCs can be delivered transcranially through the needle into deep targets, such as putamen for PD. This approach minimizes the problem that BBB could be a barrier preventing intravascularly transplanted cells from crossing the vessel wall into brain tissue [70]. It has been proposed that 100,000 surviving DA neurons per

\begin{tabular}{llll}
\hline Type of transplanted cells & $\begin{array}{l}\text { Animal } \\
\text { model }\end{array}$ & Significance & Ref.
\end{tabular}

\begin{tabular}{|c|c|c|c|c|}
\hline $\begin{array}{l}\text { Mouse fetal } \\
\text { DA neurons }\end{array}$ & $\begin{array}{l}\text { Mouse mesencephalic NSCs } \\
\text { overexpressing human glial-derived } \\
\text { neurotrophic factor (GDNF-mNSCs) }\end{array}$ & $\begin{array}{l}\text { 6-OHDA } \\
\text { rat }\end{array}$ & $\begin{array}{l}\text { Apomorphine-induced rotation was reduced } \\
\text { by co-transplantation of fetal DA neurons } \\
\text { with mNSCs genetically modified to } \\
\text { overexpress GDNF, which supports } \\
\text { differentiation into DA cells and their } \\
\text { survival. }\end{array}$ & {$[72]$} \\
\hline $\begin{array}{l}\text { Human } \\
\text { embryonic } \\
\text { NSC }\end{array}$ & $\begin{array}{l}\text { Macaque autologous Schwann cells } \\
\text { (SCs) }\end{array}$ & $\begin{array}{l}\text { 6-OHDA } \\
\text { macaque }\end{array}$ & $\begin{array}{l}\text { Gomez-Mancilla dyskinesia score in the } \\
\text { group of co-transplantation with SCs and } \\
\text { NSCs was significantly lower than the control } \\
\text { group. SCs harvested from the autologous } \\
\text { peripheral nerves can avoid rejection. }\end{array}$ & [89] \\
\hline $\begin{array}{l}\text { Human } \\
\text { umbilical } \\
\text { cord-derived } \\
\text { MSCs }\end{array}$ & Human dermal fibroblasts & MPTP rat & $\begin{array}{l}\text { Fibroblasts may be common cell contaminants } \\
\text { affecting purity of MSC preparations and } \\
\text { clinical outcome in stem cell therapy } \\
\text { protocols. }\end{array}$ & {$[90]$} \\
\hline $\begin{array}{l}\text { Rat } \\
\text { embryonic } \\
\text { DA neurons }\end{array}$ & $\begin{array}{l}\text { Rat Schwann cells (SCs) } \\
\text { overexpressing basic fibroblast growth } \\
\text { factor (FGF-2) }\end{array}$ & $\begin{array}{l}6-\mathrm{OHDA} \\
\text { rat }\end{array}$ & $\begin{array}{l}\text { Co-transplantation of DA neurons and FGF-2 } \\
\text { overexpressing SCs differentially affects } \\
\text { survival and reinnervation. Behavioral } \\
\text { recovery underlines the necessity of direct } \\
\text { contact between FGF-2 and DA neurons. }\end{array}$ & [91] \\
\hline
\end{tabular}

Table 1. Modulation of stem cells or dopaminergic (DA) cells with combined cellular transplantation in PD (adopted from "Potential of Neural Stem Cell-Based Therapy for Parkinson's Disease" [68]). 
putamen is the minimum required for a successful outcome following intracranial transplantation [71]. Bilateral injection targeting putamen is favored more than unilateral transplantation although there seems to be no consensus yet.

It is reasonable to optimize the microenvironment surrounding the transplanted NSCs or DA neurons in order to support differentiation into DA cells and their survival in vivo. A recent study demonstrates that co-transplantation of fetal DA neurons with mouse NSCs, genetically modified to overexpress human glial-derived neurotrophic factor (GDNF), mitigates motor symptoms in a rat model of PD [72]. To optimize survival and guide appropriate differentiation of grafted NSCs, ECs have been combined with NSCs for transplantation into animal brains with stroke but not yet in brains with PD [73].

\section{Application of stem cells in Parkinson's disease}

Technically DA neurons could be derived from embryonic stem cells (ESCs), mesenchymal stem cells (MSCs), umbilical cord blood hematopoietic stem cells (HSCs), and inducedpluripotent stem cells (iPSCs) generated from adult somatic cells, as well as directly from NSCs [74]. Several factors including the long-term survival and phenotype stability of stem cell-derived neurons or glial cells in the graft following transplantation, the purity of populations of cells derived from NSCs, and safety issues related to the risk of tumorigenesis have to be evaluated in greater depth [75]. An appropriate cell culture model for investigating, paracrine, autocrine, and juxtacrine signaling pathways within the neurovascular environment can provide a platform for characterizing cells with various origins and for selecting the optimal cells for transplantation [76].

NSCs derived from the whole ganglionic eminence and the ventral mesencephalon region of human fetuses have been immortalized using the technique of c-mycER transduction, and these NSC lines have been induced and differentiated to neurons potentially producing tyrosine hydroxylase (TH), a critical enzyme involved in dopamine synthesis [77, 78]. A recently devised cell culture model combined human adult brain ECs with fetal-derived NSCs which retain the ability of differentiating and further integrate together with ECs into the neurovascular tissue [79]. In this system, a distinctive neurovascular cytoarchitecture comprised of NSCs and ECs was observed. It simulates several features of the neurovascular niche, such as diffusible proteins, an extensive matrix, and expression of receptors, and genes unique to each cell type [76]. Moreover, complex multi-stage angiogenic processes can be studied by modulating the contact and soluble factor-mediated signaling pathways [76]. Studies using this NVU model will promote the best regimen for NSC-based therapies in PD [80].

Appropriate cell-to-matrix interactions are required for neurovascular tissue regeneration by NSCs and ECs. It is therefore important to investigate contact-dependent factors, including ECM components which are involved in NSC-mediated endothelial morphogenesis and vasculature shaping. ECM molecules are differentially expressed within the NVU [76] and they may have inhibitory and excitatory bioactivities. Astrocyte-derived thrombospondins, for example, have been shown to induce presynaptic differentiation in the CNS [81], but 
conversely, thrombospondin-1 functions as a negative regulator of angiogenesis [82]. The functions of these ECM molecules are associated with expression of their respective receptors, such as integrins. Most integrins recognize several ECM molecules, and most matrix molecules bind to more than one integrin. Consequently, various ECM molecules compete to bind specific integrins [83]. When studying neurovascular regeneration for NSC-based therapies in PD, an ideal in vitro NVU model should provide a system for investigating not only intercellular, but also cell-to-matrix interactions [76, 79].

\section{Perspectives on the neural stem cell-based therapy for Parkinson's disease}

Researches on pathophysiology of PD and establishment of valid and effective NSC lines will benefit from development of advanced cell culture models of the NVU. Patients with PD will have the opportunity to be treated with the cells if DA neuronal differentiation can be guided appropriately. Preclinical studies on image-guided injection and noninvasive monitoring of tissue regeneration in animal models of PD will provide the optimal therapeutic window, cell dose, and delivery route for cell transplantation [80]. Finally, appropriate patient selection and clinical follow-ups are required as a precondition for successful clinical translation of NSCbased therapies.

Recently, a preclinical study using a primate model suggests that human iPSC-derived DA progenitors are clinically applicable for the treatment of patients with PD. It was demonstrated that human iPSC-derived DA progenitor cells survived and functioned as midbrain DA neurons in a primate model of PD (Macacafascicularis) treated with the neurotoxin MPTP (1-methyl-4-phenyl-1,2,3,6-tetrahydropyridine) [84]. The therapeutic effect was consistent regardless of the origins of the cells either derived from PD patients or healthy individuals, and there was no tumor found in the brains for 2 years.

Alternatively, using parthenogenetic stem cells as a source of donor tissue have raised hopes for PD patients [85]. The parthenogenetic cells are derived from unfertilized oocytes through suppression of the second meiotic division, leading to a pluripotent diploid cell line containing exclusively maternal chromosomes [86]. They are therefore different from other pluripotent cell sources such as ESCs or iPSCs and may overcome obstacles such as the possibility of tumorigenesis. However, their lack of paternal imprinting may be associated with unique challenges in their adoption clinically as this could affect their cell cycle and differentiation capacity [87]. Notably, preparation of these cells and the transplantation procedure has to be produced under Good Manufacturing Practice (GMP) conditions, the established guidelines and safety regulations [88].

In conclusion, combined with cutting-edge technologies, including cellular reprogramming, advancement in scaffolds for brain tissue engineering, image-guided injection, and noninvasive monitoring of tissue regeneration, NSC-based therapies will alleviate symptoms of PD patients in upcoming clinical trials of cell replacement therapy once the implanted or regenerated DA neurons are integrated into the existing nigrostriatal DA pathway. 


\section{Acknowledgements}

Preparation of this article was supported by the Ministry of Science and Technology Taiwan, the Republic of China (104-2314-B-016-017-MY3) and Tri-Service General Hospital, National Defense Medical Center (TSGH-C105-085, TSGH-C107-007-007-S05, MAB-106-041, MAB-106042, and MAB-106-044). The funder had no role in the decision to publish or in manuscript preparation.

\section{Author details}

Jiunn-Tay Lee ${ }^{1,2}$, Chia-Kuang Tsai ${ }^{1,2}$ and Chung-Hsing Chou ${ }^{1,2 *}$

*Address all correspondence to: choutpe@yahoo.com.tw

1 Department of Neurology, Tri-Service General Hospital, National Defense Medical Center, Taipei, Taiwan, ROC

2 Graduate Institute of Medical Sciences, National Defense Medical Center, Taipei, Taiwan, ROC

\section{References}

[1] Tysnes OB, Storstein A. Epidemiology of Parkinson's disease. Journal of Neural Transmission. 2017;124(8):901-905

[2] de Lau LM, Breteler MM. Epidemiology of Parkinson's disease. The Lancet Neurology. 2006;5(6):525-535

[3] Mack GS. ReNeuron and StemCells get green light for neural stem cell trials. Nature Biotechnology. 2011;29(2):95-97

[4] Hoglinger GU, Rizk P, Muriel MP, Duyckaerts C, Oertel WH, Caille I, Hirsch EC. Dopamine depletion impairs precursor cell proliferation in Parkinson disease. Nature Neuroscience. 2004;7(7):726-735

[5] O'Sullivan SS, Johnson M, Williams DR, Revesz T, Holton JL, Lees AJ, Perry EK. The effect of drug treatment on neurogenesis in Parkinson's disease. Movement Disorders: Official Journal of the Movement Disorder Society. 2011;26(1):45-50

[6] Lees AJ. Unresolved issues relating to the shaking palsy on the celebration of James Parkinson's 250th birthday. Movement Disorders: Official Journal of the Movement Disorder Society. 2007;22(Suppl 17):S327-S334

[7] Nutt JG, Wooten GF. Clinical practice. Diagnosis and initial management of Parkinson's disease. The New England Journal of Medicine. 2005;353(10):1021-1027 
[8] Savica R, Rocca WA, Ahlskog JE. When does Parkinson disease start? Archives of Neurology. 2010;67(7):798-801

[9] Dijkstra AA, Voorn P, Berendse HW, Groenewegen HJ, Netherlands Brain B, Rozemuller AJ, van de Berg WD. Stage-dependent nigral neuronal loss in incidental Lewy body and Parkinson's disease. Movement Disorders: Official Journal of the Movement Disorder Society. 2014;29(10):1244-1251

[10] Schapira AH. Mitochondria in the aetiology and pathogenesis of Parkinson's disease. The Lancet Neurology. 2008;7(1):97-109

[11] Andres-Mateos E, Perier C, Zhang L, Blanchard-Fillion B, Greco TM, Thomas B, Ko HS, Sasaki M, Ischiropoulos H, Przedborski S, et al. DJ-1 gene deletion reveals that DJ-1 is an atypical peroxiredoxin-like peroxidase. Proceedings of the National Academy of Sciences of the United States of America. 2007;104(37):14807-14812

[12] Kahle PJ, Waak J, Gasser T. DJ-1 and prevention of oxidative stress in Parkinson's disease and other age-related disorders. Free Radical Biology \& Medicine. 2009;47(10):1354-1361

[13] Mantegazza AR, Marks MS. Pink light on mitochondria in autoimmunity and Parkinson Disease. Cell Metabolism. 2016;24(1):11-12

[14] Chan NC, Chan DC. Parkin uses the UPS to ship off dysfunctional mitochondria. Autophagy. 2011;7(7):771-772

[15] Surmeier DJ, Guzman JN, Sanchez-Padilla J, Goldberg JA. What causes the death of dopaminergic neurons in Parkinson's disease? Progress in Brain Research. 2010;183:59-77

[16] Boumezbeur F, Mason GF, de Graaf RA, Behar KL, Cline GW, Shulman GI, Rothman DL, Petersen KF. Altered brain mitochondrial metabolism in healthy aging as assessed by in vivo magnetic resonance spectroscopy. Journal of Cerebral Blood Flow and Metabolism: Official Journal of the International Society of Cerebral Blood Flow and Metabolism. 2010; 30(1):211-221

[17] Becker C, Jick SS, Meier CR. Use of antihypertensives and the risk of Parkinson disease. Neurology. 2008;70(16 Pt 2):1438-1444

[18] Luo J, Daniels SB, Lennington JB, Notti RQ, Conover JC. The aging neurogenic subventricular zone. Aging Cell. 2006;5(2):139-152

[19] Kempermann G, Kuhn HG, Gage FH. Genetic influence on neurogenesis in the dentate gyrus of adult mice. Proceedings of the National Academy of Sciences of the United States of America. 1997;94(19):10409-10414

[20] Tavazoie M, Van der Veken L, Silva-Vargas V, Louissaint M, Colonna L, Zaidi B, GarciaVerdugo JM, Doetsch F. A specialized vascular niche for adult neural stem cells. Cell Stem Cell. 2008;3(3):279-288

[21] Kokovay E, Goderie S, Wang Y, Lotz S, Lin G, Sun Y, Roysam B, Shen Q, Temple S. Adult SVZ lineage cells home to and leave the vascular niche via differential responses to SDF1/ CXCR4 signaling. Cell Stem Cell. 2010;7(2):163-173 
[22] Mercier F, Kitasako JT, Hatton GI. Anatomy of the brain neurogenic zones revisited: Fractones and the fibroblast/macrophage network. The Journal of Comparative Neurology. 2002;451(2):170-188

[23] Nakagomi T, Nakano-Doi A, Kawamura M, Matsuyama T. Do vascular pericytes contribute to neurovasculogenesis in the central nervous system as multipotent vascular stem cells? Stem Cells and Development. 2015;24(15):1730-1739

[24] Attwell D, Mishra A, Hall CN, O'Farrell FM, Dalkara T. What is a pericyte? Journal of Cerebral Blood Flow and Metabolism: Official Journal of the International Society of Cerebral Blood Flow and Metabolism. 2016;36(2):451-455

[25] Armulik A, Genove G, Mae M, Nisancioglu MH, Wallgard E, Niaudet C, He L, Norlin J, Lindblom P, Strittmatter K, et al. Pericytes regulate the blood-brain barrier. Nature. 2010; 468(7323):557-561

[26] Liddelow SA. Fluids and barriers of the CNS: A historical viewpoint. Fluids and Barriers of the CNS. 2011;8(1):2

[27] Reese TS, Karnovsky MJ. Fine structural localization of a blood-brain barrier to exogenous peroxidase. The Journal of Cell Biology. 1967;34(1):207-217

[28] Wolburg H, Noell S, Mack A, Wolburg-Buchholz K, Fallier-Becker P. Brain endothelial cells and the glio-vascular complex. Cell and Tissue Research. 2009;335(1):75-96

[29] Louissaint A Jr, Rao S, Leventhal C, Goldman SA. Coordinated interaction of neurogenesis and angiogenesis in the adult songbird brain. Neuron. 2002;34(6):945-960

[30] Gould E, Tanapat P, McEwen BS, Flugge G, Fuchs E. Proliferation of granule cell precursors in the dentate gyrus of adult monkeys is diminished by stress. Proceedings of the National Academy of Sciences of the United States of America. 1998;95(6):3168-3171

[31] Goldberg JS, Hirschi KK. Diverse roles of the vasculature within the neural stem cell niche. Regenerative Medicine. 2009;4(6):879-897

[32] Abbott NJ. Blood-brain barrier structure and function and the challenges for CNS drug delivery. Journal of Inherited Metabolic Disease. 2013;36(3):437-449

[33] Lippmann ES, Al-Ahmad A, Azarin SM, Palecek SP, Shusta EV. A retinoic acid-enhanced, multicellular human blood-brain barrier model derived from stem cell sources. Scientific Reports. 2014;4:4160

[34] Abbott NJ, Patabendige AA, Dolman DE, Yusof SR, Begley DJ. Structure and function of the blood-brain barrier. Neurobiology of Disease. 2010;37(1):13-25

[35] Tam SJ, Watts RJ. Connecting vascular and nervous system development: Angiogenesis and the blood-brain barrier. Annual Review of Neuroscience. 2010;33:379-408

[36] Carmeliet P, Tessier-Lavigne M. Common mechanisms of nerve and blood vessel wiring. Nature. 2005;436(7048):193-200 
[37] Stubbs D, DeProto J, Nie K, Englund C, Mahmud I, Hevner R, Molnar Z. Neurovascular congruence during cerebral cortical development. Cerebral Cortex. 2009;19(Suppl 1):i32-i41

[38] Teng H, Zhang ZG, Wang L, Zhang RL, Zhang L, Morris D, Gregg SR, Wu Z, Jiang A, Lu $\mathrm{M}$, et al. Coupling of angiogenesis and neurogenesis in cultured endothelial cells and neural progenitor cells after stroke. Journal of Cerebral Blood Flow and Metabolism: Official Journal of the International Society of Cerebral Blood Flow and Metabolism. 2008; 28(4):764-771

[39] Zehendner CM, White R, Hedrich J, Luhmann HJ. A neurovascular blood-brain barrier in vitro model. Methods in Molecular Biology. 2014;1135:403-413

[40] Shen Q, Wang Y, Kokovay E, Lin G, Chuang SM, Goderie SK, Roysam B, Temple S. Adult SVZ stem cells lie in a vascular niche: A quantitative analysis of niche cell-cell interactions. Cell Stem Cell. 2008;3(3):289-300

[41] Eichmann A, Thomas JL. Molecular parallels between neural and vascular development. Cold Spring Harbor Perspectives in Medicine. 2013;3(1):a006551

[42] Harrigan MR. Angiogenic factors in the central nervous system. Neurosurgery. 2003;53(3): 639-660. Discussion 660-631

[43] Breier G, Albrecht U, Sterrer S, Risau W. Expression of vascular endothelial growth factor during embryonic angiogenesis and endothelial cell differentiation. Development. 1992; 114(2):521-532

[44] Hogan KA, Ambler CA, Chapman DL, Bautch VL. The neural tube patterns vessels developmentally using the VEGF signaling pathway. Development. 2004;131(7):1503-1513

[45] Carmeliet P. Blood vessels and nerves: Common signals, pathways and diseases. Nature Reviews Genetics. 2003;4(9):710-720

[46] Blanco R, Gerhardt H. VEGF and Notch in tip and stalk cell selection. Cold Spring Harbor Perspectives in Medicine. 2013;3(1):a006569

[47] Tung JJ, Tattersall IW, Kitajewski J. Tips, stalks, tubes: notch-mediated cell fate determination and mechanisms of tubulogenesis during angiogenesis. Cold Spring Harbor Perspectives in Medicine. 2012;2(2):a006601

[48] Hellstrom M, Phng LK, Hofmann JJ, Wallgard E, Coultas L, Lindblom P, Alva J, Nilsson AK, Karlsson L, Gaiano N, et al. Dll4 signalling through Notch1 regulates formation of tip cells during angiogenesis. Nature. 2007;445(7129):776-780

[49] Zachary I. Neuroprotective role of vascular endothelial growth factor: signalling mechanisms, biological function, and therapeutic potential. Neuro-Signals. 2005;14(5):207-221

[50] Shen Q, Goderie SK, Jin L, Karanth N, Sun Y, Abramova N, Vincent P, Pumiglia K, Temple S. Endothelial cells stimulate self-renewal and expand neurogenesis of neural stem cells. Science. 2004;304(5675):1338-1340

[51] Gama Sosa MA, De Gasperi R, Rocher AB, Perez GM, Simons K, Cruz DE, Hof PR, Elder GA. Interactions of primary neuroepithelial progenitor and brain endothelial cells: 
Distinct effect on neural progenitor maintenance and differentiation by soluble factors and direct contact. Cell Research. 2007;17(7):619-626

[52] Hashimoto T, Zhang XM, Chen BY, Yang XJ. VEGF activates divergent intracellular signaling components to regulate retinal progenitor cell proliferation and neuronal differentiation. Development. 2006;133(11):2201-2210

[53] Ogunshola OO, Antic A, Donoghue MJ, Fan SY, Kim H, Stewart WB, Madri JA, Ment LR. Paracrine and autocrine functions of neuronal vascular endothelial growth factor (VEGF) in the central nervous system. The Journal of Biological Chemistry. 2002;277 (13):11410-11415

[54] Jin KL, Mao XO, Greenberg DA. Vascular endothelial growth factor: direct neuroprotective effect in in vitro ischemia. Proceedings of the National Academy of Sciences of the United States of America. 2000;97(18):10242-10247

[55] Singh AB, Harris RC. Autocrine, paracrine and juxtacrine signaling by EGFR ligands. Cellular Signalling. 2005;17(10):1183-1193

[56] McCarty JH. Cell adhesion and signaling networks in brain neurovascular units. Current Opinion in Hematology. 2009;16(3):209-214

[57] Bovetti S, Hsieh YC, Bovolin P, Perroteau I, Kazunori T, Puche AC. Blood vessels form a scaffold for neuroblast migration in the adult olfactory bulb. The Journal of Neuroscience: The Official Journal of the Society for Neuroscience. 2007;27(22):5976-5980

[58] Kefalopoulou Z, Aviles-Olmos I, Foltynie T. Critical aspects of clinical trial design for novel cell and gene therapies. Parkinson's Disease. 2011;2011:804041

[59] Freed CR, Greene PE, Breeze RE, Tsai WY, DuMouchel W, Kao R, Dillon S, Winfield H, Culver S, Trojanowski JQ, et al. Transplantation of embryonic dopamine neurons for severe Parkinson's disease. The New England Journal of Medicine. 2001;344(10):710-719

[60] Olanow CW, Goetz CG, Kordower JH, Stoessl AJ, Sossi V, Brin MF, Shannon KM, Nauert GM, Perl DP, Godbold J, et al. A double-blind controlled trial of bilateral fetal nigral transplantation in Parkinson's disease. Annals of Neurology. 2003;54(3):403-414

[61] Li JY, Englund E, Holton JL, Soulet D, Hagell P, Lees AJ, Lashley T, Quinn NP, Rehncrona $\mathrm{S}$, Bjorklund A, et al. Lewy bodies in grafted neurons in subjects with Parkinson's disease suggest host-to-graft disease propagation. Nature Medicine. 2008;14(5):501-503

[62] Ruggiu M, Cuccuini W, Mokhtari K, Meignin V, Peffault de Latour R, Robin M, Fontbrune FS, Xhaard A, Socie G, Michonneau D. Case report: Central nervous system involvement of human graft versus host disease: Report of 7 cases and a review of literature. Medicine. 2017;96(42):e8303

[63] Olanow CW, Gracies JM, Goetz CG, Stoessl AJ, Freeman T, Kordower JH, Godbold J, Obeso JA. Clinical pattern and risk factors for dyskinesias following fetal nigral transplantation in Parkinson's disease: A double blind video-based analysis. Movement Disorders: Official Journal of the Movement Disorder Society. 2009;24(3):336-343 
[64] Politis M, Wu K, Loane C, Quinn NP, Brooks DJ, Rehncrona S, Bjorklund A, Lindvall O, Piccini P. Serotonergic neurons mediate dyskinesia side effects in Parkinson's patients with neural transplants. Science Translational Medicine. 2010;2(38):38ra46

[65] Aldrin-Kirk P, Heuer A, Wang G, Mattsson B, Lundblad M, Parmar M, Bjorklund T. DREADD modulation of transplanted DA neurons reveals a novel parkinsonian dyskinesia mechanism mediated by the serotonin 5-HT6 receptor. Neuron. 2016;90(5):955-968

[66] Gonzalez C, Bonilla S, Flores AI, Cano E, Liste I. An update on human stem cell-based therapy in Parkinson's disease. Current Stem Cell Research \& Therapy. 2016;11(7):561-568

[67] Fan HC, Chen SJ, Harn HJ, Lin SZ. Parkinson's disease: From genetics to treatments. Cell Transplantation. 2013;22(4):639-652

[68] Chou CH, Fan HC, Hueng DY. Potential of neural stem cell-based therapy for Parkinson's disease. Parkinson's Disease. 2015;2015:571475

[69] Ishikawa H, Tajiri N, Shinozuka K, Vasconcellos J, Kaneko Y, Lee HJ, Mimura O, Dezawa M, Kim SU, Borlongan CV. Vasculogenesis in experimental stroke after human cerebral endothelial cell transplantation. Stroke: A Journal of Cerebral Circulation. 2013;44(12): 3473-3481

[70] Pendharkar AV, Chua JY, Andres RH, Wang N, Gaeta X, Wang H, De A, Choi R, Chen S, Rutt BK, et al. Biodistribution of neural stem cells after intravascular therapy for hypoxicischemia. Stroke; a Journal of Cerebral Circulation. 2010;41(9):2064-2070

[71] Ambasudhan R, Dolatabadi N, Nutter A, Masliah E, McKercher SR, Lipton SA. Potential for cell therapy in Parkinson's disease using genetically programmed human embryonic stem cell-derived neural progenitor cells. The Journal of Comparative Neurology. 2014; 522(12):2845-2856

[72] Deng X, Liang Y, Lu H, Yang Z, Liu R, Wang J, Song X, Long J, Li Y, Lei D, et al. Cotransplantation of GDNF-overexpressing neural stem cells and fetal dopaminergic neurons mitigates motor symptoms in a rat model of Parkinson's disease. PLoS One. 2013; 8(12):e80880

[73] Nakagomi N, Nakagomi T, Kubo S, Nakano-Doi A, Saino O, Takata M, Yoshikawa H, Stern DM, Matsuyama T, Taguchi A. Endothelial cells support survival, proliferation, and neuronal differentiation of transplanted adult ischemia-induced neural stem/progenitor cells after cerebral infarction. Stem Cells. 2009;27(9):2185-2195

[74] Petit GH, Olsson TT, Brundin P. The future of cell therapies and brain repair: Parkinson's disease leads the way. Neuropathology and Applied Neurobiology. 2014;40(1):60-70

[75] Kim SU, Lee HJ, Kim YB. Neural stem cell-based treatment for neurodegenerative diseases. Neuropathology: Official Journal of the Japanese Society of Neuropathology. 2013; 33(5):491-504

[76] Chou CH, Modo M. Human neural stem cell-induced endothelial morphogenesis requires autocrine/paracrine and juxtacrine signaling. Scientific Reports. 2016;6:29029 
[77] El-Akabawy G, Medina LM, Jeffries A, Price J, Modo M. Purmorphamine increases DARPP32 differentiation in human striatal neural stem cells through the Hedgehog pathway. Stem Cells and Development. 2011;20(11):1873-1887

[78] Vernon AC, Smith EJ, Stevanato L, Modo M. Selective activation of metabotropic glutamate receptor 7 induces inhibition of cellular proliferation and promotes astrocyte differentiation of ventral mesencephalon human neural stem/progenitor cells. Neurochemistry International. 2011;59(3):421-431

[79] Chou CH, Sinden JD, Couraud PO, Modo M. In vitro modeling of the neurovascular environment by coculturing adult human brain endothelial cells with human neural stem cells. PLoS One. 2014;9(9):e106346

[80] Smith EJ, Stroemer RP, Gorenkova N, Nakajima M, Crum WR, Tang E, Stevanato L, Sinden JD, Modo M. Implantation site and lesion topology determine efficacy of a human neural stem cell line in a rat model of chronic stroke. Stem Cells. 2012;30(4):785-796

[81] Christopherson KS, Ullian EM, Stokes CC, Mullowney CE, Hell JW, Agah A, Lawler J, Mosher DF, Bornstein P, Barres BA. Thrombospondins are astrocyte-secreted proteins that promote CNS synaptogenesis. Cell. 2005;120(3):421-433

[82] Chu LY, Ramakrishnan DP, Silverstein RL. Thrombospondin-1 modulates VEGF signaling via CD36 by recruiting SHP-1 to VEGFR2 complex in microvascular endothelial cells. Blood. 2013;122(10):1822-1832

[83] Schottelius M, Laufer B, Kessler H, Wester HJ. Ligands for mapping alphavbeta3-integrin expression in vivo. Accounts of Chemical Research. 2009;42(7):969-980

[84] Kikuchi T, Morizane A, Doi D, Magotani H, Onoe H, Hayashi T, Mizuma H, Takara S, Takahashi R, Inoue $\mathrm{H}$, et al. Human iPS cell-derived dopaminergic neurons function in a primate Parkinson's disease model. Nature. 2017;548(7669):592-596

[85] Barker RA, Parmar M, Kirkeby A, Bjorklund A, Thompson L, Brundin P. Are stem cellbased therapies for Parkinson's disease ready for the clinic in 2016? Journal of Parkinson's Disease. 2016;6(1):57-63

[86] Revazova ES, Turovets NA, Kochetkova OD, Kindarova LB, Kuzmichev LN, Janus JD, Pryzhkova MV. Patient-specific stem cell lines derived from human parthenogenetic blastocysts. Cloning and Stem Cells. 2007;9(3):432-449

[87] Hernandez L, Kozlov S, Piras G, Stewart CL. Paternal and maternal genomes confer opposite effects on proliferation, cell-cycle length, senescence, and tumor formation. Proceedings of the National Academy of Sciences of the United States of America. 2003;100(23): 13344-13349

[88] Stephenson E, Jacquet L, Miere C, Wood V, Kadeva N, Cornwell G, Codognotto S, Dajani $Y$, Braude P, Ilic D. Derivation and propagation of human embryonic stem cell lines from frozen embryos in an animal product-free environment. Nature Protocols. 2012;7(7):1366-1381 
[89] Xia Y, Jiang C, Cao Z, Shi K, Wang Y. Co-transplantation of macaque autologous Schwann cells and human embryonic nerve stem cells in treatment of macaque Parkinson's disease. Asian Pacific Journal of Tropical Medicine. 2012;5(1):7-14

[90] Pereira MC, Secco M, Suzuki DE, Janjoppi L, Rodini CO, Torres LB, Araujo BH, Cavalheiro EA, Zatz M, Okamoto OK. Contamination of mesenchymal stem-cells with fibroblasts accelerates neurodegeneration in an experimental model of Parkinson's disease. Stem Cell Reviews. 2011;7(4):1006-1017

[91] Timmer M, Muller-Ostermeyer F, Kloth V, Winkler C, Grothe C, Nikkhah G. Enhanced survival, reinnervation, and functional recovery of intrastriatal dopamine grafts cotransplanted with Schwann cells overexpressing high molecular weight FGF-2 isoforms. Experimental Neurology. 2004;187(1):118-136 